\title{
EXPLORING THE RELATIONSHIP BETWEEN LEXICAL ACCESS AND PROFICIENCY LEVEL IN L2 SPEECH PRODUCTION
}

\section{EXPLORANDO A RELAÇÃO ENTRE ACESSO LEXICAL E NÍVEL DE PROFICIÊNCIA NA PRODUÇÃO ORAL EM L2}

\author{
Gicele V. V. Prebianca*
}

\begin{abstract}
This study explores the relationship between lexical access and proficiency level in L2 speech production. Forty-one participants (intermediate and advanced learners of English as a foreign language) performed a lexical access task in L2 which yielded two measures: reaction time (RT) and naming accuracy (NA). The statistical analysis point to a facilitatory effect of semantic related word distractors on L2 picture-naming for the experimental and control conditions in both proficiency groups. In addition, only the mean difference in NA scores for the control and experimental conditions between proficiency groups reached statistical significance. That is, advanced learners overpassed the intermediate ones in number of words correctly named. Results also indicate a partial relationship between RT and NA scores. Findings are explained in light of research on L2 speech production, lexical access and working memory, taking into account the development of L2 proficiency and L2 lexical representations.
\end{abstract}

Keywords: lexical access; proficiency level; L2 speech production.

\section{RESUMO}

O presente estudo explora a relação entre acesso lexical e nível de proficiência na produção oral em L2. Quarenta e um participantes (aprendizes de nível intermediário e avançado de Inglês como língua estrangeira) executaram uma tarefa de acesso lexical em L2 que resultou na análise de duas medidas: tempo de reação (TR) e acurácia de nomeação (AN). As análises estatísticas apontam para um efeito facilitatório dos distratores semanticamente relacionados na nomeação das figuras em L2 para ambos os grupos - experimental e controle - em ambos os níveis de proficiência. Os resultados também revelaram que somente a diferença de média nos escores de AN para as condições controle e experimental entre os níveis de proficiência foi significativa. Ou seja, aprendizes de nível avançado nomearam um maior número de figuras corretamente em comparação aos de nível intermediário. Os resultados ainda indicam a uma relação parcial entre os escores de TR e AN. Os achados são discutidos

* IFC, Blumenau (SC), Brasil. gicelevpreb@gmail.com

1 The term L2 is used in this paper to refer to a language someone speaks (or learns) other than his/her mother tongue. 
a luz das teorias sobre produção oral em L2, acesso lexical e memória de trabalho, levandose em consideração o desenvolvimento da proficiência e das representações lexicais em L2. Palavras-chave: acesso lexical; nível de proficiência; produção oral em L2.

\section{INTRODUCTION}

According to Levelt (1989), speaking is a cognitive demanding task which requires the execution of several mental activities carried out by autonomous processing components working in tandem to achieve the final goal. For him, speakers are information-processors who manipulate information cognitively in order to produce speech. In his L1 model of speech production, Levelt proposes that speaking involves, mainly three processes: the conceptualization of a message, the selection of lexical items and the encoding of their grammatical and phonological features and, finally, message articulation (LEVELT, 1989).

Among the processes involved in the production of speech, Levelt considers the selection of the lexical items the most important one. According to him, it is through lexical selection (access) that all syntactic and phonological information is added to the pre-verbal message which will later become overt speech. In the present study, lexical access is seen as the act of "retrieving a word [...] from the mental lexicon, given a lexical concept to be expressed" (LEVELT, ROLOEFS, MEYER, 1999, p. 4).

Because lexical access processing is central to the elaboration of speech, it is crucial to understand how speakers retrieve from long-term memory the lexical items that will realize their communicative intentions. In addition, because L2 speakers' knowledge of the foreign language tends to be, in great part, of an explicit type, there seems to be room to suspect that the cognitive demands of the L2 lexical access process might be even greater in different levels of proficiency, once less proficient bilingual speakers might possess more explicit and less automatized knowledge of the language. This is in line with the notion that grammar knowledge is not fully developed in L2 and that the L2 mental lexicon might possess fewer and less specified lexical items (POULISSE, 1997), rendering L2 speaking an even more controlled attention task.

An important ongoing debate regarding lexical access in L2 speech production focuses on whether words from the two languages get activated and compete for selection - the parallel activation hypothesis. According to this hypothesis, activation spreads from the conceptual system (considered to store common concepts for bilingual speakers) to the lexical system regardless of the 
language in which the speaker wants to communicate, therefore activating all the corresponding and related lexical nodes both in L1 and L2. As lexical selection is assumed to be dependent on the level of activation of both the target lexical node and the non-target nodes, bilingual speakers not only have to select the right lemma node under competition but also have to do so in the right language if crosslinguistic interference is to be avoided (COSTA, COLOMÉ, CARAMAZZA, 2000).

Two proposals have been offered to solve the issue of lexical selection in the appropriate language. The first one is the language non-specific hypothesis in which inhibitory mechanisms are assumed to suppress the activation of the non-target language (DE BOT, 1992; GREEN, 1986; POULISSE, BONGAERTS, 1994). According to this hypothesis, activation spreads to all lexical nodes of a bilingual's two languages and the proper selection is guaranteed by inhibitory mechanisms. Thus, when verbalizing the word dog, activated competitors such as cat, fish e cão, for example, are suppressed and dog is selected. Conversely, according to the language-specific hypothesis only the lexical nodes of the target language are considered for selection.

Empirical studies on L2 lexical access have concentrated on examining whether lexical items from L1 and L2 are concurrently activated when only one language is being used. Both the language-specific and the language non-specific hypotheses have been tested under the picture-word interference paradigm. In this paradigm normally speakers are presented with a picture to be named accompanied by a word distractor to be ignored. For L2 lexical access investigation, word distractors have been presented in the language not-in-use both in a semanticallyrelated condition and in an unrelated-condition. Overall results indicate semantic interference (inhibition) when distractors are presented in L2 thus, suggesting that lexical items for both L1 and L2 compete for selection, giving support to the language non-specific hypothesis (COSTA et al., 2000). However, these results are inconclusive once, as explained by Costa et al, the semantic inhibitory effect observed may also be due to competition of lexical nodes of the same language. As for instance, if one is expected to name a pictured dog in English and is presented with the word distractor gato (cat) in Spanish, the semantic characteristics of gato will also activate the lemma node for CAT, which in turn may interfere in the selection of DOG.

The issue of whether the lexical items of both languages of bilingual speakers are indeed activated (thus, competing for selection) remains unresolved. Clearly, more research is needed to unveil the effects of semantically related distractors on 
L2 picture-naming and, consequently, on L2 lexical access. Therefore, I propose to investigate the possible effects of presenting semantically related word distractors in the language-in-use. Moreover, trying to go deeper into the issue, I propose to look at two different variables, namely response time (RT) and naming accuracy (NA) so as to verify whether inhibitory and/or facilitatory effects hold similarly for the time taken to name pictures and for the number of pictures correctly named.

The main hypothesis underlying this investigation is that there will be an inhibitory effect of semantically related word distractors displayed 100 ms before picture onset on mean reaction time and naming accuracy scores in L2 lexical access of intermediate and advanced EFL learners (Hypothesis 1). In addition, it is predicted that advanced learners will be faster and more accurate than intermediate ones when naming pictures both in the control condition and experimental condition (under the interference of semantically related word distractors displayed $100 \mathrm{~ms}$ before picture onset) (Hypothesis 2). Also, there will be a relationship between reaction time and naming accuracy scores in L2 lexical access in intermediate and advanced proficiency levels (Hypothesis 3).

\section{METHOD}

\subsection{Participants}

Forty-one Brazilian-Portuguese native speakers enrolled at an English course of a private English School volunteered to participate in the present study. The pool consisted of 15 male and 26 female students with ages ranging between 13 and 44 . Participants were divided into two groups according to their level of proficiency intermediate and advanced. The intermediate group consisted of 19 students and the advance of 22. Proficiency level was not assessed by standardized proficiency tests in the present study. It was assumed, on the other hand, that they had already been submitted to placement tests by the time they started their English classes. This was, in fact, a common practice adopted by the Language School students were attending classes at in order to minimize the chances of having different proficiency-level students in the same class. Therefore, the only formal criterion used for assigning participants to intermediate and advanced groups was to verify in which level students were enrolled at their English courses a week before starting the data collection. 


\subsection{The experiment}

Participants performed a lexical access task in L2 in which they were required to name pictures in the presence and absence of word distractors (the experimental and control conditions, respectively). Pictures portrayed concrete objects visually presented as black line drawings on white backgrounds and should be named as fast and accurately as possible. Word distractors also referred to concrete objects and were of two different types: (1) semantically related and (2) unrelated to the name of the picture. Distractors were presented in three different points in time, following the Stimulus Onset Asynchrony Paradigm (SOA). Word distractors appeared together with the picture $(S O A=0), 100 \mathrm{~ms}$ before picture onset $(S O A=-100)$ and $100 \mathrm{~ms}$ after picture onset $(\mathrm{SOA}=+100)$. All word distractors and names of the pictures were monosyllabic words. Semantically related distractors were words from the same category such as dog and cat. Unrelated words were used together with filler pictures and were not included in the analysis (see Appendix A for the stimuli used in this task). So as to test for any kind of semantically effect on lexical access, only data regarding semantically related word distractors presented $100 \mathrm{~ms}$ before picture onset were taken into consideration.

Four lexical access measures were obtained through the picture-naming task: reaction time scores for the control and experimental conditions and, naming accuracy scores for the control and experimental conditions (see Appendix B for individual scores on the lexical access task). Pictures were named in a control condition, that is, without any word distractor presentation, in order to generate a baseline measure to be compared with reaction time and naming accuracy measures produced by participants when naming pictures in the face of interfering stimuli. Naming accuracy was operationalized as the number of pictures participants were able to name correctly, regardless of how long they took to name them.

\subsection{Procedures}

All participants were tested individually. They received instructions in their L1 (Portuguese), followed by a block of practice composed by twenty pictureword pairs. The pictures for the training session were displayed with superimposed unrelated word distractors presented together with the picture onset. The pictures and word distractors of the training session were not used in the main experiment. Following Costa, Miozzo and Caramazza (1999), participants were informed that they would see picture-word pairs and that their task was to name the pictures as 
fast and accurately as possible. They were also told to try to ignore the words and avoid hesitations and self-corrections and/or repetitions while performing the task.

Pictures were divided into 3 sets - a set of 22 target pictures displayed in the experimental and control conditions, a set of 30 filler pictures to complete the experimental condition, and a set of 20 training pictures to be presented in the training session. Fillers and training pictures were paired with unrelated word distractors. In total, participants saw 72 different pictures and produced 264 vocal responses. The experiment was developed and run using E-prime 1.2 in a laptop Compaq nx6115. Naming accuracy measures were collected with the help of a tape recorder. Data was analyzed quantitatively through statistical procedures namely Descriptive Statistics, T-tests and Pearson Correlations. Results are reported in the next section of this paper.

\section{RESULTS}

\subsection{Lexical access and proficiency - reaction time and naming accuracy scores}

One of the main goals of this study was to investigate whether L2 lexical access in intermediate and advanced learners, as measured by reaction time and naming accuracy scores, was similarly affected by the presentation of semantically related word distractors. Therefore, in order to pursue the aforementioned objective, descriptive statistics for reaction time (RT) and naming accuracy (NA) variables in both conditions - control and experimental -, were run (see Appendix $\mathrm{B}$ for individual scores on these variables). Table 1 displays the results.

Table 1. Descriptive statistics for RT and NA variables in the intermediate and advanced groups

\begin{tabular}{lrrrrrrrr}
\hline & $\begin{array}{c}\text { Mini- } \\
\text { mum }\end{array}$ & $\begin{array}{l}\text { Maxi- } \\
\text { mum }\end{array}$ & Mean & Std. Dev & $\begin{array}{c}\text { Skewe- } \\
\text { ness }\end{array}$ & $\begin{array}{c}\text { Std. } \\
\text { Error }\end{array}$ & Kurtosis & $\begin{array}{c}\text { Std. } \\
\text { Error }\end{array}$ \\
\hline Intermediate Group & & & & & & & \\
\hline RTcontr & 702.36 & 1248.50 & 966.02 & 151.22 & -.310 & .536 & -.458 & 1.038 \\
RTexp & 688.00 & 1000.76 & 846.02 & 97.75 & -.256 & .536 & -.838 & 1.038 \\
NAcon- & 8.00 & 20.00 & 14.05 & 3.63 & -.190 & .536 & -.947 & 1.038 \\
tr & & & & & & & & \\
NAexp & 10.00 & 22.00 & 16.27 & 2.84 & -.299 & .536 & .700 & 1.038 \\
N=18 & & & & & & & & \\
\hline
\end{tabular}




\begin{tabular}{lrrrrrrrr}
\hline \multicolumn{7}{l}{ Advanced Group } \\
\hline RTcontr & 522.82 & 1075.12 & 900.33 & 151.87 & -1.011 & .491 & .349 & .953 \\
RTexp & 537.64 & 965.16 & 796.25 & 114.46 & -.190 & .491 & -.352 & .953 \\
NAcontr & 10.00 & 22.00 & 16.81 & 3.26 & -.465 & .491 & -.619 & .953 \\
NAexp & 15.00 & 22.00 & 18.95 & 2.12 & -.294 & .491 & -.951 & .953 \\
N=22 & & & & & & & & \\
\hline
\end{tabular}

As can be seen in Table 1, intermediate and advanced groups' scores were found to be normally distributed in all variables. For the RT control (RTcontr) and experimental (RTexp) variables, minimum and maximum scores could vary from 0 to 1500 milliseconds, which was the interval of time participants had to name each picture. In this case, higher scores represent longer reaction time; whereas lower scores correspond to faster responses. The total number of target pictures to be named in each condition (control and experimental) was 22, therefore NA scores could vary between 0 and 22 . Whereas the maximum score was obtained by both proficiency groups, as can be observed in the above table, the intermediate group got the lowest minimum score -10.00 .

An interesting result displayed in Table 1 is the fact that RT scores in the control condition were higher than RT scores in the experimental condition in both proficiency groups $(M=966.02$ to 846.02 for the intermediate group, and $M=1075.12$ to 965.16 for the advanced group), which indicates that participants took longer to name pictures without any interfering stimuli than when the pictures were presented with word distractors. The same pattern was found for NA scores $(M=14.05$ to 16.27 for the intermediate group, and $M=16.81$ to 18.95 for the advanced group), suggesting that both intermediate and advanced participants named more pictures correctly in the presence of interfering stimuli than when no distractor was presented.

As revealed by the descriptive statistical analysis, there is a mean difference between RT and NA scores in the control and experimental conditions for both proficiency groups - intermediate and advanced. In order to check if this difference is statistically significant, Paired Sample T-tests were applied to the data. The initial prediction was that there would be an inhibitory effect of semantically related word distractors on mean reaction time and naming accuracy scores (Hypothesis 1). As can be observed in Table 2, this prediction was not confirmed. 
Table 2. Paired sample t-tests for RT and NA control and experimental scores in the intermediate and advanced groups

\begin{tabular}{lllll}
\hline $\begin{array}{l}\text { Paired } \\
\text { Differences }\end{array}$ & & & \\
\hline Mean St. Dev. & T & df & $\begin{array}{c}\text { Sig. } \\
(2 \text {-tailed })\end{array}$ \\
\hline
\end{tabular}

\begin{tabular}{|c|c|c|c|c|c|c|}
\hline & Intermediate Group & & & & & \\
\hline & RTcontr X RTexp & 119.99 & 140.91 & 3.61 & 17 & $.002 *$ \\
\hline & $\begin{array}{r}\text { NAcontr X } \\
\text { NAexp }\end{array}$ & -2.22 & 2.60 & -3.62 & 17 & $.002 *$ \\
\hline \multicolumn{7}{|l|}{$\mathrm{N}=18$} \\
\hline \multicolumn{7}{|l|}{$* \mathrm{p}<0,05$} \\
\hline \multicolumn{7}{|c|}{ Advanced Group } \\
\hline & RTcontr X RTexp & 104.07 & 133.60 & 3.65 & 21 & $.001^{*}$ \\
\hline & $\begin{array}{r}\text { NAcontr X } \\
\text { NAexp }\end{array}$ & -2.13 & 2.33 & -4.29 & 21 & $.000^{*}$ \\
\hline \multicolumn{7}{|l|}{$\mathrm{N}=22$} \\
\hline$* \mathrm{p}<0,05$ & & & & & & \\
\hline
\end{tabular}

RTcontr = mean reaction time in the control condition

RTexp = mean reaction time in the experimental condition

NAcontr = mean naming accuracy in the control condition

$\mathrm{NA}=$ mean naming accuracy in the experimental condition

Results of the Paired Sample T-tests show that the decrease in the mean RT scores in both intermediate and advanced groups is statistically significant: $t(17)$ $=119.99, p<.05$ for the intermediate group, and $t(21)=104.07, p<.05$ for the advanced group. The same pattern holds for NA scores in both proficiency groups for the increase in mean scores reached statistical significance: $t(17)=-2.22, p<.05$ for the intermediate group, and $t(21)=-2.13, p<.05$ for the advanced group.

Taken together, the just reported results reaffirm that intermediate and advanced learners were both faster and more accurate when naming pictures under interference. This finding points to a facilitatory effect of semantically related word distractors presented $100 \mathrm{~ms}$ before picture onset, as opposed to the inhibitory effects found in L1 lexical access research (SCHRIEFERS et al., 1990; LEVELT et al., 1991a, 1991b; ROELOFS, 1992), thus rejecting Hypothesis 1. I will return to this issue in the Discussion section of this paper. 
Although Paired Sample T-tests have shown a facilitatory effect of semantically related word distractors presented $100 \mathrm{~ms}$ before picture onset on RT and NA scores within proficiency levels, it was still not possible to know which proficiency group had the best performance in terms of response time and correct responses. Thus, in order to address hypothesis 2 , which predicted that advanced learners would be faster and more accurate when naming pictures with and without interference, Independent Sample T-tests were run (the assumption of equal variances for Independent $T$-tests was satisfied). Results are given in Table 3.

Table 3. Independent sample t-tests for RT and NA control and experimental scores in the intermediate and advanced groups

\begin{tabular}{cccc}
\hline $\begin{array}{c}\text { T-test for the } \\
\text { equality of } \\
\text { means }\end{array}$ & & & \\
\hline Mean differences & $\mathrm{t}$ & $\mathrm{df}$ & $\begin{array}{c}\text { Sig. } \\
\text { (2-tailed) }\end{array}$ \\
\hline 65.69 & 1.364 & 38 & .181 \\
49.76 & 1.459 & 38 & .153 \\
-2.76 & -2.531 & 38 & $.016^{*}$ \\
-2.67 & -3.404 & 38 & $.002^{*}$ \\
\hline & & & \\
\hline
\end{tabular}

${ }^{*} \mathrm{p}<0,05$

RTcontr = mean reaction time in the control condition

RTexp $=$ mean reaction time in the experimental condition

NAcontr = mean naming accuracy in the control condition

$N A=$ mean naming accuracy in the experimental condition

As can be seen in Table 3, the means for the control and experimental conditions did not differ significantly in terms of reaction time between proficiency groups: $t(38)=65.69, p>.05$ for the RTcontr scores, and $t(38)=49.76, p>.05$ for RTexp scores. Conversely, mean differences in terms of correct responses between proficiency groups were proved to be statistically significant: $t(38)=-2.76, p<.05$ for NAcontr scores, and $t(38)=-2.67, p<.05$ for NAexp scores. These results show that, although advanced learners were able to name pictures faster than intermediate learners in both control and experimental conditions, this tendency has to be seen with caution, since this difference did not reach significance. However, the statistically significant mean difference between NA scores of advanced and 
intermediate learners show that the former were more accurate than the latter when naming pictures both with and without interference. Overall, it seems that advanced learners presented a better performance in L2 lexical access than intermediate learners. Thus, according to the results just presented, Hypothesis 2 is only partially supported.

Another aim pursued by the present study was to verify if reaction time and naming accuracy scores were both good predictors of L2 lexical access. Hypothesis 3 predicted that there would be a statistically significant relationship between these two variables in intermediate and advanced groups. If that hypothesis is confirmed, naming accuracy might be considered (besides the traditionally used RT measures) a powerful measure for future investigations seeking to scrutinize lexical access processes in L2 speech production. In order to address Hypothesis 3, Pearson Correlations were run. Table 4 shows that there were no statistically significant correlations between RT and NA scores in the intermediate group. This result suggests that the intermediate participants of the present study behaved differently in terms of response time and number of words named accurately. That is to say, not all participants who had the lowest RT scores also had the highest NA scores. As previously explained, RT scores could vary from 0 to $1500 \mathrm{~ms}$. So, the higher the score, the longer the time needed to respond to the stimuli. As for NA scores, the higher the scores, the greater the total number of words named accurately. The same seems to hold for the RTexp scores in relation to NAcontr and NAexp scores in the advanced group.

Nevertheless, significant, moderate and negative correlations were found between RTcontr and NAcontr $-\mathrm{N}(22)=-.636 p<.05$, and RTcontr and NAexp $-\mathrm{N}(22)=-.719 p<.05$, in the very same group, indicating a similar behavior of advanced participants regarding response time (RTcontr) and number of pictures correctly named with and without interference (NAcontr and NAexp). The fact that these variables were operationalized in an opposite fashion, made the correlations negative. Summing up, the prediction that RT and NA scores would be significantly related in both proficiency groups (Hypothesis 3) was just partially supported by the results of the present study. Therefore, the use of NA scores as the only measure of lexical access in L2 speech production has to be seen with caution. 
Table 4. Pearson product moment coefficient of correlation for RT and NA scores in the intermediate and advanced groups

\begin{tabular}{ccc|cc}
\hline & \multicolumn{2}{c|}{ Intermediate } & \multicolumn{2}{c}{ Advanced } \\
\cline { 2 - 5 } & NAcontr & NAExp & NAcontr & NAexp \\
RTcontr & -.276 & -.192 & $-.636^{* *}$ & $-.719^{* *}$ \\
RTexp & -.459 & -.199 & -.234 & -.316 \\
\hline$* * \mathrm{p}<.01$ & $\mathrm{~N}=18$ & $\mathrm{~N}=22$ & \\
\hline
\end{tabular}

RTcontr = mean reaction time in the control condition

RTexp $=$ mean reaction time in the experimental condition NAcontr = mean naming accuracy in the control condition $N A=$ mean naming accuracy in the experimental condition

\subsection{Discussion}

The discussion in this sub-section seeks to explain the results of the present study regarding lexical access and proficiency level in L2 speech production. To reiterate, hypothesis 1 predicted that there would be a statistically significant inhibitory effect of semantically related word distractors displayed $100 \mathrm{~ms}$ before picture onset on mean reaction time and naming accuracy scores in L2 lexical access of intermediate and advanced learners. Results of paired sample T-tests showed a statistically mean difference between RT and NA scores for the experimental and control conditions in both proficiency groups, indicating that the intermediate and advanced participants of the present study named pictures faster and more accurately in the presence of interference, thus refuting Hypothesis 1.

Hypothesis 2 predicted that advanced learners would be faster and more accurate than intermediate learners when naming pictures in the control and experimental conditions. This prediction was partially supported for only the mean difference in NA scores for the control and experimental conditions between proficiency groups reached statistical significance. In what follows, I will attempt to explain the facilitatory effect on picture naming and advanced learners' better performance on NA scores in light of research on L2 speech production, lexical access and working memory.

According to the comparison of means between RT and NA scores of both proficiency groups for the experimental and control conditions, there is no inhibitory effect of semantically related word distractors on mean reaction time and naming accuracy scores in L2 lexical access of intermediate and advanced learners. Results revealed the mean difference between these scores (RT and NA) were 
statistically significant, pointing to a facilitatory effect of semantic related word distractors presented $100 \mathrm{~ms}$ before picture onset. This result goes against the findings of $\mathrm{L} 1$ lexical access research, which found longer reaction times for picture naming when semantically related distractors were presented slightly before picture onset (SCHRIEFERS et al. 1990; LEVELT et al., 1991a, 1991b; ROELOFS, 1992).

The discrepancy between the findings of picture naming in L1 and L2 yielded by the results of the present study might be simply due to the fact that, as highlighted by Poulisse (1997), bilingual speech production has its own intrinsic characteristics, standing in itself as a particular cognitive endeavor in which the knowledge base is supposedly incomplete and underdeveloped in terms of lexical and grammatical structures. As a consequence, bilingual speakers seem to have a mental lexicon composed by a reduced number of lexical items which, in turn, may lack semantic, syntactic and phonological specifications. The underspecified semantic information of lexical items may affect their relationship with one another in the mental lexicon network (POULISSE, 1993). In other words, because the semantic links of L2 lexical items are not fully established, the connections among them in the mental lexicon are likely to be weak. The lack of strong semantic connections for the L2 lexical items stored in L2 learners' mental lexicon might be related to their less automatized knowledge of the L2. Empirical evidence suggests that bilingual lexical representations differ and develop between and within bilingual speakers (DE GROOT, 1995; DE GROOT, HOEKS, 1995). The current view is consistent with the developmental model of bilingual lexicosemantic organization advocated by de Groot (1995) and de Groot and Hoeks (1995). In this model, the lexical connections in the bilingual mental lexicon develop in a somewhat continuous fashion, from weak and indirect links to strong and direct links between words and their conceptual representations (meanings). According to de Groot, such developmental change is mediated by bilinguals' proficiency level. That is, a less proficient bilingual memory is composed by two word stores (L1 and L2 lexicons) and a single common conceptual store with access to meaning occurring via L2/L1 associative links (the word-association hypothesis). Because the conceptual store is shared between the two languages and because the L1 lexicon is likely to contain stronger, direct and automatic links with the conceptual store (HEREDIA, 1996), it is probable that so as to understand and produce L2 words, a less proficient bilingual needs to access L1 meaning first.

On the other hand, in a highly proficient bilingual memory although the L1 and L2 mental lexicons also share the same conceptual store, the access to meaning is not mediated by L1 lexical representations anymore. Instead, conceptual meaning 
is accessed via strong and direct connections between words and the conceptual store in each of the languages (the concept-mediation hypothesis). That is to say, comprehending and speaking in L2 for high proficient bilinguals is likely to occur in a similar fashion as comprehending and producing speech in L1. According to de Groot (1995) and de Groot and Hoeks (1995), bilingual speakers would start accessing L2 meaning via L1 representations at the word level, but with practice they would develop stronger and direct connections between the L2 lexical and the conceptual stores. The extent to which the connections among L2 lexical items and conceptual representations are strengthened seems to depend on the extent to which the L2 is practiced. Practice, as proposed by Anderson (1983), is what leads to knowledge proceduralization in skill acquisition through consistently repeating and applying the necessary production rules for its execution, thus resulting in automatic performance. In this sense, it seems that more automatized L2 knowledge produces, through practice, stronger links between L2 lexical items and their conceptual representations, and among L2 lexical items themselves, thus leading to the conclusion that if the L2 lexicon lacks strong semantic/conceptual connections it is probably due to its less automatized nature as compared to that of the L1 lexicon. The idea that the L2 lexicon might be less automatized than the L1 lexicon leads to an important implication for the results of the present study regarding the semantic facilitatory effect observed in RT and NA scores for intermediate and advanced learners. It might be reasonable to expect that because the $\mathrm{L} 2$ lexicon lacks automatization, the process of accessing and retrieving a particular L2 lexical item occurs in a controlled serial fashion as opposed to the parallel automatic access in L1 speech production (LEVELTt, 1989). Support in favor of this argument comes from Unsworth and Engle $(2006 ; 2007)$ who demonstrated that retrieval of information from secondary memory, that is, from information outside the focus of attention (WM) - probably stored in long-term memory -, is governed by a discrimination process that involves the use of adequate contextual cues and controlled attention. Those contextual cues are set by the task context and determine what information is relevant for the retrieval process and what must be displaced. Success in retrieval, as proposed by Unsworth and Engle (2007), depends on individuals' ability to use contextual cues effectively to delimit the search set. That is to say, the greater the number of items activated by the contextual cues and consequently included in the search set, the lower the probability that retrieval will occur fast and accurately.

Considering retrieval from secondary memory as a controlled serial search (UNSWORTH, ENGLE, 2006, 2007; ROSEN, ENGLE, 1997, 1998), it seems plausible to suggest that lexical access in L2, depending on semantic/conceptual 
representations less automatized than their L1 counterparts, also qualifies as a controlled serial search task. Because of this, any word distractor semantically related presented before picture onset would help learners to execute the serial search for the name of the picture, facilitating performance. In other words, distractors semantically related to target pictures are likely to belong to the same semantic field in the mental lexicon and may have served as a cue for learners so as to delimit the search set adequately. Once the search set was efficiently delimited, sampling and retrieval became easier. Without that cue, learners of the present study would have to search the L2 mental lexicon more extensively (and possibly the L1 as well in the case of intermediate learners) for the correct lexical item, which would probably be more time-consuming, increasing their reaction times and chances for error. To reiterate, I hypothesized that RT and NA scores were facilitated by the presentation of semantically related word distractors because access and retrieval of L2 items implies a controlled serial search process in which each single item has to be verified one after another until the right one is selected for verbalization. In this sense, presenting semantically related word distractors as cues helped learners to focus attention on a specific set of items, constraining the number of options and thus leading to a faster and more accurate retrieval.

Another issue of interest in the present study concerned whether there would be any difference in RT and NA for the experimental and control conditions due to proficiency level. It was previously hypothesized (Hypothesis 2) that advanced learners would name pictures faster and more accurately both in the absence and presence of interfering stimuli than intermediate learners. As demonstrated by the results of the Independent-sample T-tests, no mean difference between RT scores for intermediate and advanced learners reached statistical significance. On the other hand, the mean difference between NA scores for both proficiency groups was statistically significant, indicating that advanced learners named more pictures correctly than intermediate learners. One reason that could account for by this result is the fact that advanced learners may have a greater knowledge of the L2 in relation to intermediate learners. In other words, they may know more L2 lexical items in a more deeply fashion (WOLTER, 2001) 2 .

The fact that advanced and intermediate learners did not significantly differ in RT scores might be an indication of trade-off effects between time spent to

2 Although Wolter (2001) does not explicitly states what to know a word deeply is, I assume that depth of word knowledge is related to the knowledge one has of the semantic, syntactic and phonological features of a particular word stored in the mental lexicon. Besides, I support Eckle and Garret's (1998) idea that knowing a word means recognizing its meaning and being able to retrieve it from memory in order to produce it verbally. 
respond to the target pictures and number of correct responses. Several models of WMC (DANEMAN, CARPENTER, 1980; TURNER, ENGLE, 1989; CONWAY, ENGLE，1996; KANE, BECKLEY, CONWAY, ENGLE，2001; ENGLE，2002), based on information-processing theories (McLAUGHLIN, HEREDIA, 1996), support the notion that the cognitive system responsible for the processing and storage of information in human beings (WM) is attentional limited. That is to say, there are not enough attentional resources to be devoted to these two computations (storage and processing) at the same time. Due to attentional limitations, even with a higher WMC than intermediate learners, the advanced learners of the present study might have chosen to devote attention to that aspect of the task which seemed more relevant to them - naming the pictures accurately -, thus penalizing response time. This explanation seems to account for both the lack of statistically significant mean differences between RTcontr and RTexp scores for proficiency levels, and also the lack of statistically significant correlations between RT and NA scores in the intermediate and advanced groups, as I will attempt to demonstrate in the next paragraph and in the following sub-section, respectively.

The finding that intermediate and advanced learners of the present study did not differ significantly in terms of response time when naming pictures with and without the presentation of interfering stimuli may support the model of retrieval proposed by Rosen and Engle (1998). According to the results of a series of pairedassociate tasks carried out by the authors, retrieval involves four main components: spreading activation, monitoring, selective suppression, and controlled search. Spreading activation is taken by Rosen and Engle as being an automatic process in nature - a process that "results from the presentation of a cue" (p. 432). In the case of the picture-naming task of the present study, spreading activation was triggered by the presentation of the picture in the control condition and by the presentation of the word distractors and the picture in the experimental condition. Monitoring, the second component of retrieval, is necessary to guarantee the right choice is made so that any inadequate or incorrect response is retrieved. According to Rosen and Engle, monitoring takes time to operate since it requires controlled attention. Once this component fails, interference of unwanted elements may occur. When naming the pictures, participants of this investigation were expected to be able to monitor their lexical choices in order to name the pictures as fast and accurately as possible. The third component - selective suppression - is also a controlled process. That is, without being able to regulate and devote their attentional resources to the task of suppressing irrelevant information, the participants of the present study might not have been able to perform the naming task at all. However, as 
shown by the above reported results, this performance was found to differ in many aspects. In the picture-naming task performed by the participants of this study, selective suppression played a major role in preventing irrelevant information from being activated by contextual cues and included in the search set (UNSWORTH, ENGLE, 2006; 2007).

The forth component proposed by Rosen and Engle refers to controlled search. As the name suggests, this process requires controlled attention in order to ensure the search and selection of the correct response to be verbalized. When the participants of the present study had to retrieve the $\mathrm{L} 2$ names for the depicted pictures, they certainly engaged in controlled search, which required them to verify each lexical item activated by the semantically related word distractors in a serial fashion thus taxing WM resources to a greater extent. Under cognitive pressure and without enough attentional resources to devote to all processes involved in retrieving a word, both intermediate and advanced learners of the present study might have chosen to prioritize just one of the aspects of the task - naming pictures accurately -, in this case.

Furthermore, in light of the results of the present investigation, it is also possible to affirm that there is not a linear relationship between reaction time and naming accuracy scores in L2 lexical access of intermediate and advanced learners. Pearson correlations showed only statistically significant correlations between RT scores for the control condition, and NA scores for both control and experimental conditions in the advanced group, indicating that intermediate participants were not able to name pictures quickly and accurately at the same time neither in the control nor in the experimental condition. On the other hand, advanced participants named pictures faster and more accurately only in the control condition. This result goes just partially in line with Hypothesis 3 which had predicted there would be a relationship between RT and NA scores for both proficiency groups.

Again, I hypothesize that, due to limited WMC to execute the attentional demanding processes of word retrieval - monitoring, selective suppression, and controlled search (ROSEN, ENGLE, 1997; 1998) -, the participants of the current study were unable to name pictures correctly in a short interval of time thus, giving priority to just one aspect of the task - response time or naming accuracy.

Summing up, as evidenced by the results of the present study, the facilitatory effect of semantically related word distractors on L2 picture-naming, the lack of correlation between RT and NA scores in the intermediate and advanced groups, and the variation on L2 WMC scores appear to be mediated by proficiency level. As suggested by De Bot and Schereuder (1993), L2 proficiency might, to some 
still unknown extent, impact on several L2 language production sub-processes to different degrees. This assumption lends itself to further investigation once the results of the present study show a tendency towards a possible interaction between RT and NA scores, WMC and proficiency level in L2 speech production.

\section{FINAL REMARKS}

The present study represents an attempt to further investigate the possible semantic interference effects on picture-naming, an issue that has apparently been neglected on L2 lexical access research agenda. Moreover, it is, to the best of my knowledge the first study to propose how reaction time and naming accuracy scores co-vary during L2 lexical access with and without interference and how they would possibly be affected by learners' proficiency level.

Overall, the findings suggest that bilingual lexical access seems to differ in some aspects across proficiency levels in terms of retrieval speed and naming accuracy. However, such differences might only be a function of greater knowledge and automatization of the language (L2) or even consequences of some kind of practice effect caused by the order in which the conditions in the picture naming task were implemented.

This study suffered from two major limitations. First, no standardized proficiency test was applied prior to data collection in order to classify participants as intermediate and advanced ones. Instead, the only measure of proficiency adopted was the one used by their English school to assign them to different language-level classes. Therefore, further investigations should consider having another measure of proficiency so as to minimize proficiency issues.

Second, participants of the present study totaled $41-19$ intermediate and 22 advanced ones. It might be interesting to have a greater sample size for future studies so as to observe whether the facilitatory effect of semantically related word distractors on L2 picture-naming and the lack of correlation between RT and NA scores in the intermediate and advanced groups still persist. Another suggestion would be to add a more elementary proficiency level in order to verify whether similar patterns regarding reaction time and naming accuracy scores are observed. 


\section{REFERENCES}

ANDERSON, J. R. (1983). The architecture of cognition. Cambridge, MA: Harvard University Press.

CONWAY, A. R. A.; ENGLE, R. W. (1996). Individual differences in working memory capacity: More evidence for a general capacity theory. Memory, 4, pp. 577-590.

COSTA, A.; CARAMAZZA, A.; SEBASTIAN-GALLÉS. (2000). The Cognate Facilitation Effect: Implications for Models of lexical Access. Journal of Experimental Psychology: Learning, Memory and Cognition 26(5), pp. 1283-1296.

COSTA, A.; COLOMÉ, A.; CARAMAZZA A. (2000). Lexical access in speech production: the bilingual case. Psicológica, 21, pp. 403-437.

COSTA, A.; MIOZZO, M.; CARAMAZZA, A. (1999). Lexical selection in: do words in bilingual's two lexicons compete for selection? Journal of Memory and Language, 41, pp. 365-397.

DANEMAN, M. \& CARPENTER, P. A. (1980). Individual differences in working memory and reading. Journal of Verbal Leaning and Verbal Bebaviour, 19, pp. 450-466.

DE BOT, K. (1992). A Bilingual Production Model: Levelt's 'Speaking' Model adapted. Applied Linguistics, 13,1, pp. 1-24.

DE BOT, K.; SCHREUDER, R. (1993). Word Production and the Bilingual Lexicon. In Schreuder, R. \& Welten, B. (Eds.) The Bilingual lexicon. Amsterdam: John Benjamins.

DE GROOT, A. M. B.; HOEKS, J. C. J. (1995). The development of bilingual memory: evidence for word translation by trilinguals. Language Learning, 45, 4, pp. 683-724.

DE GROOT, A. M. B. (1995). Determinants of bilingual lexicosemantic organization. Computer Assisted Language Learning, 8, 2-3, pp. 151-180.

ENGLE, R. W. (2002). Working memory capacity as executive attention. Current Directions in Psychological Science, 11, pp. 19-23.

GREEN, D. W. (1986). Control, activation and resource: a framework and a model for the control of speech in bilinguals. Brain and Language, 27, pp. 210-223.

HEREDIA, R. R. (1996). Bilingual Memory: a re-revised version of the hierarchical model of bilingual memory. The Newsletter of the Center for Research in Language, 10, pp. 3-6.

KANE, M. J.; BECKLEY, K. M.; CONWAY, A. R. A.; ENGLE, R. W. (2001). A controlledattention view of working-memory capacity. Journal of Experimental Psychology: General, 130, pp. 169-183.

LEVELT, W. J. M. (1989). Speaking: from intention to articulation. The Speaker as Information Processor. Cambridge, MA: MIT Press.

LEVELT, W. J. M.; ROELOFS, A.; MEYER, A. (1999). A theory of lexical access in speech production. Behavioral and Brain Sciences, 22, pp. 1-75.

LEVELT, W. J. M.; SCHRIEFERS, H.; VORBERG, D.; MEYER, A. S.; PECHMANN, T.; HAVINGA, J. (1991b). Normal and deviant lexical processing: a reply to Dell and O’Seaghdha. Psychological Review, 98, pp. 615-618. 
LEVELT, W. J. M.; SCHRIEFERS, H.; VORBERG, D.; MEYER, A. S.; PECHMANN, T.; HAVINGA, J. (1991a). The time course of lexical access in speech production: a study of picture-naming. Psychological Review, 98, pp. 122-142.

McLAUGHLIN, B.; HEREDIA, R. (1996). Information-processing approaches to research on second language acquisition and use. In: Ritchie, W. \& Bhatia, T. (Eds.) Handbook of second language acquisition. San Diego: Academic Press, pp. 213-228.

POULISSE, N.; BONGAERTS, T. (1994). First language use in second language production. Applied Linguistics, 15, pp. 36-57.

POULISSE, N. A. (1993). Theoretical Account of Lexical Communication Strategies. In: Schreuder, R. \& Weltens, B. (Eds.) The Bilingual lexicon (pp. 157-190). Amsterdam: John Benjamins.

POULISSE, N. Language Production in Bilinguals. (1997). In: De Groot, A. M. B. \& Kroll, J. F. (Eds.) Tutorials in bilingualism: psycholinguistic perspectives. Mahwah, N. J.: LEA, pp. $201-224$.

ROELOFS, A. (1992). A spreading-activation theory of lemma retrieval in speaking. Cognition, 42, pp. 107-142.

ROSEN, V. M.; ENGLE, R. W. (1998). Working memory capacity and suppression. Journal of Memory and Language, 39, pp. 418-436.

ROSEN, V. M.; ENGLE, R. W. (1997). The role of working memory capacity in retrieval. Journal of Experimental Psychology: General, 126, pp. 211-227.

SCHRIEFERS, H.; MEYER, A. S.; LEVELT, W. J. M. (1990). Exploring the time course of lexical access in language production: picture-word interference studies. Journal of Memory and Language, 29, pp. 86-102.

TURNER, N.; ENGLE, R. (1989). Is working memory capacity task-dependent? Journal of Memory and Language, 28, pp. 127-154.

UNSWORTH, N.; ENGLE, R.W. (2006). A temporal-contextual retrieval account of complex span: An analysis of errors. Journal of Memory and Language, 54, pp. 346-362.

UNSWORTH, N.; ENGLE, R.W. (2007). The nature of individual differences in working memory capacity: active maintenance in primary memory and controlled search from secondary memory. Psychological Review, 114, pp. 104-132.

WOLTER, B. (2001). Comparing the L1 and L2 mental lexicon: a depth of individual word knowledge model. SSLA, 23, pp. 41-69. 
Appendix A: Stimuli for the Lexical Access Tasks

\begin{tabular}{|c|c|c|c|}
\hline $\begin{array}{l}\text { Control and Experi- } \\
\text { mental Conditions } \\
\text { Lexical items (pic- } \\
\text { tures) }\end{array}$ & $\begin{array}{l}\text { Semantically related } \\
\text { word distractors }\end{array}$ & $\begin{array}{c}\text { Fillers } \\
\text { Lexical Items (pic- } \\
\text { tures) }\end{array}$ & $\begin{array}{l}\text { Unrelated word } \\
\text { distractors }\end{array}$ \\
\hline Bee & Honey & Tree & Light \\
\hline Plane & Fly & Lamp & Sock \\
\hline Ball & Soccer & Grape & Cup \\
\hline Cake & Birthday & Box & Cow \\
\hline Knife & Fork & Bed & Ice \\
\hline Chair & Table & pig & Pencil \\
\hline Dog & Cat & bear & Table \\
\hline House & Apartment & finger & night \\
\hline Car & Motorcycle & fish & clock \\
\hline Hat & Head & bag & moon \\
\hline Key & Door & flower & ball \\
\hline Moon & Sun & hook & kiss \\
\hline Hand & Finger & book & tail \\
\hline Eye & Mouth & sock & bridge \\
\hline Egg & Chicken & boy & bell \\
\hline Cat & Dog & table & leaf \\
\hline Belt & Pants & bird & shoe \\
\hline Sun & Rain & bread & rope \\
\hline Glass & Water & pan & foot \\
\hline Pen & Pencil & plant & chair \\
\hline Door & Window & fork & eye \\
\hline \multirow[t]{9}{*}{ Leaf } & Tree & frog & knee \\
\hline & & roof & silk \\
\hline & & pear & bike \\
\hline & & train & rose \\
\hline & & cow & shirt \\
\hline & & vase & tie \\
\hline & & chess & belt \\
\hline & & king & mop \\
\hline & & nurse & fish \\
\hline
\end{tabular}


Exploring the relationship between lexical acess...

\begin{tabular}{|l|l|l|l|}
\hline \multicolumn{2}{|c|}{$\begin{array}{c}\text { Training block } \\
\text { Lexical items } \\
\text { (pictures) }\end{array}$} & \multicolumn{2}{c|}{ Unrelated word distractors } \\
\hline ring & boot & bed & key \\
\hline boat & Rat & pear & glass \\
\hline heart & ghost & bull & bank \\
\hline shark & Tent & cake & nose \\
\hline rain & Bus & hand & knife \\
\hline clock & Bat & bear & nail \\
\hline fire & foot & vase & rice \\
\hline wall & mug & hat & church \\
\hline bridge & tower & tooth & car \\
\hline bull & cup & tower & bat \\
\hline
\end{tabular}


Appendix B: Individual Scores on the Lexical Access Task

\begin{tabular}{|l|l|l|l|l|l|l|l|l|l|}
\hline \multicolumn{9}{|c|}{ Intermediate Group } & \multicolumn{5}{c|}{ Advanced Group } \\
\hline & RTcontr & RTexp & $\begin{array}{c}\text { NA- } \\
\text { contr }\end{array}$ & NAexp & & RTcontr & RTexp & $\begin{array}{c}\text { NA- } \\
\text { contr }\end{array}$ & NAexp \\
\hline Part & & & & & Part & & & & \\
\hline 1 & 972,94 & 855,17 & 17,00 & 17,00 & 2 & 748,90 & 790,19 & 19,00 & 20,00 \\
\hline 7 & 1109,92 & 857,05 & 16,00 & 17,00 & 3 & 917,18 & 956,75 & 16,00 & 17,00 \\
\hline 8 & 780,63 & 688,00 & 16,00 & 17,00 & 4 & 919,10 & 965,16 & 19,00 & 18,00 \\
\hline 9 & 1093,67 & 904,50 & 8,00 & 12,00 & 5 & 988,11 & 893,67 & 18,00 & 21,00 \\
\hline 11 & 1110,22 & 715,92 & 18,00 & 17,00 & 6 & 821,95 & 770,86 & 21,00 & 21,00 \\
\hline 12 & 702,36 & 893,71 & 12,00 & 16,00 & 10 & 1066,73 & 698,63 & 13,00 & 15,00 \\
\hline 13 & 1248,50 & 994,55 & 12,00 & 15,00 & 14 & 981,87 & 751,86 & 12,00 & 18,00 \\
\hline 17 & 1086,92 & 1000,76 & 10,00 & 16,00 & 15 & 1035,64 & 819,24 & 13,00 & 17,00 \\
\hline 19 & 1053,50 & 827,06 & 19,00 & 22,00 & 16 & 1022,60 & 957,63 & 12,00 & 18,00 \\
\hline 22 & 918,50 & 940,59 & 12,00 & 16,00 & 18 & 1004,13 & 653,75 & 15,00 & 17,00 \\
\hline 23 & 953,00 & 837,35 & 17,00 & 20,00 & 20 & 614,90 & 665,90 & 20,00 & 21,00 \\
\hline 24 & 1003,22 & 927,18 & 10,00 & 10,00 & 21 & 1053,78 & 892,29 & 20,00 & 20,00 \\
\hline 26 & 970,59 & 912,39 & 16,00 & 18,00 & 25 & 843,92 & 726,24 & 19,00 & 20,00 \\
\hline 29 & 9999,00 & 9999,00 & 9999,00 & 9999,00 & 27 & 1075,12 & 713,20 & 16,00 & 18,00 \\
\hline 33 & 1059,00 & 866,41 & 8,00 & 16,00 & 28 & 764,00 & 741,26 & 20,00 & 21,00 \\
\hline 34 & 748,26 & 724,00 & 15,00 & 19,00 & 30 & 731,10 & 704,64 & 19,00 & 22,00 \\
\hline 35 & 963,42 & 754,07 & 14,00 & 13,00 & 31 & 1014,00 & 878,53 & 17,00 & 15,00 \\
\hline 38 & 891,33 & 689,50 & 13,00 & 14,00 & 32 & 958,67 & 956,79 & 16,00 & 18,00 \\
\hline 40 & 722,09 & 840,27 & 20,00 & 18,00 & 36 & 782,67 & 787,11 & 16,00 & 21,00 \\
\hline & & & & & 37 & 981,18 & 853,81 & 17,00 & 20,00 \\
\hline & & & & & 39 & 958,91 & 802,56 & 10,00 & 17,00 \\
\hline & & & & & 41 & 522,82 & 537,64 & 22,00 & 22,00 \\
\hline
\end{tabular}

Recebido: 09/07/2013

Aceito: 21/08/2014 